\title{
Variação fonético-fonológica na música popular nordestina
}

\author{
Phonological-phonetic variation in Northeastern popular music
}

\author{
Gilvan da Costa Santana* \\ Universidade Federal da Babia \\ Salvador, Bahia, Brasil
}

\begin{abstract}
Resumo: Lançamos mão, neste estudo, de conceitos relevantes enfatizados pela Sociolinguística, relacionandoos a músicas do cancioneiro nordestino brasileiro, objetivando a construção de conhecimentos que se contraponham a preconceitos de ordem social e linguística, por reconhecimento de legitimidade das variações diatópicas. Esta abordagem visa fomentar o respeito à identidade sociolinguística. Para tanto, interessou-nos, precipuamente, verificar e analisar a presença de variação fonético-fonológica e figuras de dicção ou metaplasmos em textos clássicos do cancioneiro nacional-regional, tais como: Asa Branca, Assum Preto e Sussuarana. Nessa perspectiva, compositores de origem nordestina como Luiz Gonzaga, Humberto Teixeira, Heckel Tavares, Luiz Peixoto, dentre tantos outros, legitimam a realidade diatópica e diastrática do Brasil por meio da canção popular, a despeito de todo e qualquer preconceito sociolinguístico ainda renitente. Salientamos, por fim, que, para consecução de tal intento, nossa pesquisa estabelece diálogo com as contribuições de Amadeu Amaral, Antenor Nascentes e, especificamente, Mário Marroquim.
\end{abstract}

Palavras-chave: Sociolinguística. Língua Nordestina. MPB. Variação Diatópica. Variação Diastrática.

Abstract: In this study, we have used relevant concepts emphasized by Sociolinguistics, relating them to songs from the Brazilian Northeastern Songbook, aiming at the construction of knowledge that opposes social and linguistic prejudices, by recognizing the legitimacy of diatopic variations. This approach aims to foster respect for sociolinguistic identity. In order to do so, we were interested in the analysis and analysis of the presence of phonological-phonetic variation and figures of diction or metaplasmos in classic texts of the national-regional songbook, such as: Asa Branca, Assum Preto and Sussuarana. In this perspective, composers of northeastern origin such as Luiz Gonzaga, Humberto Teixeira, Heckel Tavares and Luiz Peixoto, among others, legitimize the diatopic and diastrática reality of Brazil through the popular song, in spite of any and all reluctant sociolinguistic prejudice. Finally, we point out that, in order to achieve this, our research establishes a dialogue with the contributions of Amadeu Amaral, Antenor Nascentes and, specifically, Mário Marroquim.

Keywords: Sociolinguistics. Northeastern Language. MPB. Diatopic Variation. Diastrática Variation.

* Doutorando em Língua e Cultura na UFBA, professor do Instituto Federal de Sergipe. E-mail: gilvancsantana@yahoo.com.br 


\section{CONSIDERAÇÕES INICIAIS}

A Sociolinguística trouxe aos estudos linguísticos no Brasil rica contribuição ao valorizar e considerar o uso da língua no contexto espacial, na própria prática da língua cotidiana, a língua vernacular. Nessa perspectiva, valorizam-se situações concretas de integração de falantes, entendendo e produzindo enunciados adequados aos diversos contextos (cf. FREITAG, 2016). O grande mérito desses estudos, a nosso ver, está no resgate, na valorização e no respeito dos diversos falares regionais diatópicos, sem estabelecer juízos de valor. Nesse sentido, faz-se mister o combate efetivo a todo e qualquer preconceito linguístico. Consoante Mattos e Silva (2006), variações fônicas regionais não marcam níveis sociais nem escolares nem etários, mas, mesmo assim, sofrem preconceito em relação ao português urbano do Sul-Sudeste em detrimento do Norte-Nordeste e do Centro-Oeste:

[...] as realizações variadas de pretônicas opõem, grosso modo, Norte e Sul do Brasil; marcam paulistas por oposição a cariocas as sibilantes e estes com realizações chiantes; opõem certas áreas, sobretudo do Sul, em relação ao resto do Brasil, a inexistência da distinção entre duas realizações do $\mathrm{r}$ intervocálico, um anterior outro posterior e assim por diante. (MATTOS E SILVA, 2006, p. 69)

Estudos acerca de preconceitos linguísticos, tais como os de Bagno (2009) e de Leite (2012), apontam que a língua do nordestino sofre uma série de discriminações e estigmatização: feia, errada, pobre, matuta etc. A sustentação dessa visão estereotipada se dá pela mídia em geral (rádio, jornal, revista, tv, internet etc) e, infelizmente, pela escola, pois são veículos que ratificam tal visão pejorativa de 'língua errada', de classes economicamente subalternas, de elementos atrasados e rústicos do interior. Consequentemente, denigre-se e renega-se a identidade cultural do grupo de falantes, em vez de reconhecer-se a diversidade linguística e combater a discriminação ligada à variação espacial tão rica. No processo de reconhecimento e valorização da variedade linguística nordestina, juntamente com a Sociolinguística, é preciso relevar as contribuições da Dialetologia, que iniciam antes mesmo da formalização dos estudos linguísticos no Brasil, como apresentamos no retrospecto a seguir.

\section{HISTÓRICO ACERCA DOS ESTUDOS DIALETOLÓGICOS NO BRASIL}

A partir da leitura de Cardoso (2010), Ferreira e Cardoso (1998) e Aguillera (2005), podemos ter uma visão panorâmica concernente aos estudos dialetológicos no Brasil, a partir de uma cronologia marcada e demarcada por 4 fases. A seguir, destacaremos os aspectos mais relevantes concernentes a essa periodização. Convém frisar que Ferreira e 
Cardoso reformulam a clássica periodização proposta por Antenor Nascentes, que estabeleceu apenas duas grandes fases.

Vale ressaltar o fato de Nascentes considerar apenas 2 fases por ele ter apresentando a sua proposta em 1952, o que implica dizer que tais estudos dialetológicos não ainda haviam sido implementados e atingido processos de incessante evolução nas pesquisas na área da geolinguística no Brasil. Trata-se de uma limitação meramente cronológica.

Há um consenso por parte dos historiadores da Dialetologia em considerar marco da primeira fase o lançamento da obra $A$ manifestação de natureza dialetal sobre o português do Brasil, de Domingos Borges de Barros, o Visconde de Pedra Branca, em 1826. Essa primeira fase dos estudos recobre um século e estende-se de 1826 a 1920, com ênfase no dialeto caipira, com destaque ao estudo lexicográfico do português no interior do Brasil. Isso se dá por meio da publicação de dicionários, glossários e vocabulários regionais. Eis aí a característica fundamental desse primeiro momento da Dialetologia do Brasil: estudos de natureza mais ampla e de cunho gramatical.

Nesse bojo, temos $O$ idioma do hodierno Portugal comparado com o Brasil, escrito pelo brasileiro José Jorge Paranhos da Silva (1879). Essa obra trata dos diferentes aspectos da variação do português do Brasil em relação ao português de Portugal. O mérito desse trabalho está no estudo da pronúncia dos vocábulos, sinalizando as diferentes marcas de variação diatópica portuguesa e brasileira. A partir, sobretudo, dessa perspectiva e das análises lexicográficas, semânticas e morfossintáticas, o autor infere que o português brasileiro é mais vocálico, silábico, compassado, sonoro e doce que o português lusitano.

Em seguida, temos como marco da segunda fase a publicação de $O$ dialeto caipira, de Amadeu Amaral, em 1920. Essa fase estende-se até 1952, momento em que se dão os primeiros passos para o sistemático desenvolvimento da geolinguística em território brasileiro. Configura-se essa fase segunda de estudos de Dialetologia no Brasil pela produção de trabalhos de cunho monográfico voltados para a observação de uma área determinada, buscando descrever os fenômenos que a caracterizam não só do ponto de vista semântico-lexical, mas também fonético-fonológico e morfossintático.

Surge aí uma metodologia de abordagem dos fenômenos para o exame da realidade observada in loco. Nessa ótica, merecem destaque, além dos trabalhos de Amadeu Amaral, já citado, os estudos de Antenor Nascentes e Mario Marroquim. Fato inconteste é que esse período trouxe uma nova ótica ao exame da realidade linguística brasileira, dados os diferentes níveis de enfoque da língua.

Assim, $O$ dialeto caipira já mostra o processo de dialetação do português brasileiro, do interior do Estado de São Paulo, numa época em que pouco se sabia sobre o tema e que quase nada se tinha escrito sobre tal assunto. Chega a causar uma certa estranheza encontrar-se um estudo tão meticuloso e metódico numa época de tão parcos recursos que viabilizassem tamanha empreitada. Ainda nessa segunda fase da Dialetologia Brasileira, dois anos depois de publicado $O$ dialeto caipira, Antenor Nascentes publica $O$ 
linguajar carioca em 1922, obra que, a partir da segunda edição, passa a chamar-se simplesmente O linguajar carioca (1953)

Dessa feita, o objetivo de Nascentes era a busca de definição para o que entende por "falar brasileiro" para situar a variedade carioca nesse falar. Na verdade, o projeto de Antunes era bem mais ambicioso: uma divisão dos falares brasileiros, açambarcando todo o país. O mais curioso é que, até os dias hoje, a divisão geolinguística proposta por Antenor Nascentes é considerada atual, em termos de aspectos da fonética, da morfologia, da sintaxe e do léxico.

Constatamos que a tríade fundamental para se entenderem os avanços trazidos por essa segunda fase se forma com Mario Marroquim e A lingua do Nordeste, publicada em 1934. Enquanto Amaral e Antunes se debruçaram sobre dialetos da região Sudeste, Marroquim se volta ao estudo de dialetos nordestinos, centrando-se em Alagoas e Pernambuco. É certo que os autores ora destacados tinham a dimensão de que a enorme extensão geográfica em que o português é falado no Brasil dá a cada região peculiaridades e modismos desconhecidos nas outras.

Como prova de quão profícua foi a segunda fase dos estudos dialetológicos brasileiros, temos, além dessas vultosas três obras relacionadas, que destacar outras: obras sobre léxicos e glossários regionais: Vocabulário gaúcho, 1926, vocabulário do Nordeste do Rio Grande do Sul; linguagem dos praieiros: O vocabulário pernambucano, 1937; Obras de caráter geral numa perspectiva mais ampla e globalizante: O português do Brasil, 1940, de Silvio Elia; A língua do Brasil, 1946, de Gladstone Chaves de Melo; Estudos de caráter regional, fenômenos específicos de cada região: O falar mineiro, 1938, e Estudos de dialetologia portuguesa: a linguagem de Goiás, 1944, de José Aparecido Teixeira; A linguagem popular da Babia, 1951, de Edison Carneiro; Estudos específicos sobre a contribuição africana.

Já em se tratando de terceira fase dos estudos dialetológicos neste país, o marco é documental: o decreto n ${ }^{\circ}$ 30.643, de 20 de março de 1952, de Getúlio Vargas, definindo as finalidades da comissão de Filologia, assentando como a principal delas a elaboração do Atlas linguístico do Brasil. Não se pode deixar de mencionar para essa terceira fase o pioneirismo de nomes, tais quais: Antenor Nascentes, Serafim da Silva Neto, Celso Cunha e Nelson Rossi. Trata-se de novo momento para a Dialetologia Brasileira, pois se dá o início dos estudos de geografia linguística.

Antenor Nascentes tem papel preponderante nesse processo ao publicar as Bases para a elaboração do atlas linguísticos do Brasil, obra em dois volumes: o primeiro lançado em 1958 e o segundo, em 1961. A ideia é genial, certamente, pois pretende um atlas feito, ao mesmo tempo, para todo o país. Em contrapartida, esbarra na impossibilidade de sua concretização por motivos óbvios: extensão territorial gigantesca, verba sempre exígua para projeto de tal magnitude, falta de mão de obra especializada que atenda a tal demanda em termos de domínio de métodos e práticas de pesquisa com tal configuração etc. 
Ante essa realidade, Celso Cunha sugere, com Serafim da Silva Neto, em 1957, construção de atlas regionais. Porém, o primeiro passo concreto, no campo da geolinguística, vem a ser dado por Nelson Rossi, que publica, com a coautoria de Dinah Isensee e Carlota Ferreira, em 1963, o Atlas dos falares baianos. Empreitada dialetológica na Bahia, tornando-se pioneira na aplicação da geografia linguística no Brasil.

Em síntese, a terceira fase tem como marca identificadora o começo dos estudos sistemáticos no campo da geografia linguística. É claro que nesse período ainda persistem os estudos de natureza teórica, a produção de léxicos regionais e de glossários, bem como a elaboração de monografias sobre regiões diversas. Consoante proposta de Ferreira e Cardoso, o terceiro momento, que se inicia em 1952, encerra-se em 1996.

Por fim, a quarta fase dos estudos de Dialetologia Brasileira se introduz por ocasião do IV Congresso Internacional da Associação Brasileira de Linguística (Brasília, fevereiro de 2005), haja vista que Mota e Cardoso propuseram a delimitação do Projeto Atlas Linguísticos do Brasil. Por ser a fase atual dos estudos, esse quarto momento da Dialetologia no Brasil ainda suscitará registros históricos mais detidos. Indubitável é a retomada da ideia de realização de um atlas linguístico geral do Brasil e a concretização de um projeto especifico com esse objetivo.

Indubitavelmente, o grande relevo no que concerne aos estudos de variação diatópica e diastrática no Brasil se dá a partir da década de 1960 pela incorporação e implementação dos princípios da Sociolinguística, que abandona a visão monodimensional tradicionalista da geolinguística.

\section{A LÍNGUA DO NORDESTE BRASILEIRO}

Marroquim (1934) representa o pioneirismo na contribuição aos estudos dialetológicos do Brasil. Ele já detectava nos anos de 1930 fenômenos caracterizadores da língua nordestina que são até hoje estudados. Naquela época, o autor conseguiu elaborar um vultoso trabalho manual, sem aparatos tão fundamentais ao trabalho com Dialetologia, como gravador, tampouco computador ou smartphone.

Dessa forma, a obra de Mário Marroquim, A lingua do nordeste, mostrou, há tantas décadas, a força e o vigor do dialeto rotulado como popular, regional, provinciano, analfabeto, "matuto". A despeito dessa forma preconceituosa como grande parte da elite e intelectualidade define o vernáculo interiorano nordestino, há toda uma corrente da Dialetologia e da Sociolinguística que considera tratar-se da força ao idioma, causando "turbulência" pela diversidade e recusando uniformização, academicismo, padrões urbanos de "refinamento".

Para Marroquim (1934), o vernáculo nordestino representa o dialeto brasileiro, nossa verdadeira língua: saborosa, cotidiana, uma língua brasileira, bem diferente da prosódia portuguesa. Para ele, a língua nordestina apresenta variações e demarcações a 
partir de grupos de influências, que incluem Estados de regiões fronteiriças, a saber: Pernambuco - grupo de falares da Paraíba, do Rio Grande do Norte, do Ceará, do Acre. Bahia - grupo de falares de Sergipe, Alagoas, Espírito Santo.

Nessa ótica do autor, o ‘divisor de águas’ é o Rio São Francisco, a partir de 1501. Segundo Marroquim, é marca fundamental do vernáculo nordestino, "língua matuta", a conservação de formas originais do Séc. XVI, arcaísmos, ao contrário do dialeto tido como culto, que se vai modificando e atualizando por motivos vários, sobretudo, seu não isolamento e sua abertura evidente aos vários efeitos de comunicação, tecnologia, mobilidade espacial etc.

Considerando os estudos dialetológicos acerca do português nordestino, sobretudo a obra aqui destacada, notamos fenômenos até hoje caracterizadores dessa variedade típica regional no Nordeste do Brasil. Assim é que, mesmo hodiernamente, no que tange a aspectos fonológicos, a pronúncia nordestina do Brasil é tida como "arrastada, cantada", em contraposição com o português de Portugal, considerado "áspero, enérgico". Vejamos a seguir os casos mais evidentes dessa variação diatópica que marca a fala nordestina.

Em se tratando de aspectos morfológicos, quanto a questões de gênero, segundo Marroquim (1934), para o povo, substantivo uniforme não existe; daí porque diabo diaba/ monstro - monstra/ senvergonho - senvergonha/ ladrão - ladrona; já em relação a número, a flexão fica no plano do determinativo: os patrão/ os pão/ as minina/ os home/ dois pire/ cinco lápi; já no que se refere a grau, o superlativo é preferencialmente analítico; inferimos, então, que se evita, portanto, a sofisticação do uso de sufixos, muito caros às formas tidas como cultas.

Quanto à Lexicologia, Mário Marroquim lembra que o vocabulário do interior conserva muito do português arcaico; lembra, também, a importância dos processos de derivação e composição na formação da maioria das palavras de nosso léxico; acrescenta a esses recursos a influência do estrangeirismo somado ao tupi e a africanismos, sobretudo para topônimos, termos e utensílios de caça, pesca etc.

Ademais, já naquela época, o autor constata que, na sintaxe, há muita aproximação da variedade nordestina com o que se chama de desvios nas diversas regiões do Brasil, tais quais: concordâncias sem respeitar regras estabelecidas pela gramática; emprego de pronomes, como se vê em: Eu lhe vi/ eu vi ele/ mandou eu sair/ (acusativos/ nominativos/dativos); emprego de pronome obliquo clítico; ter em vez de haver; verbo de movimento com EM no lugar de A: descer/ chegar/ ir em, dentre tantos outros aspectos que ferem os preceitos da chamada língua padrão, culta, escrita.

Diante dos estudos sobre o português nordestino aqui referenciados, constatamos que, embora haja especificidades de aspectos lexicais, morfológicos e sintáticos, está no plano fonético-fonológico a maior diversidade de recursos e caracteres distintivos. Embora retrate um estado linguístico que remonta ao início do século XX, os fenômenos 
linguísticos elencados nos estudos de Mário Marroquim ainda se verificam nas observações do vernáculo do Nordeste de hoje; vejamos os quadros 1 a 4 .

$\mathrm{I}=\mathrm{I}(\mathrm{n})$ legal / I(n)greja/ (In)diota/ (In)gnorante/ / (In)guá/ (In)lusão/ (In)lustre
$\mathrm{E}=$ (In)ducação/ (in)logio/ (in)zame/ (in)zempro/ (in)zistir/ (in)leição
$\mathrm{EM} \mathrm{=} \mathrm{(im)prego/} \mathrm{(im)baraço/} \mathrm{(in)sinar/} \mathrm{(in)cubação/} \mathrm{(in)cruzilhada/} \mathrm{(in)costo}$
Perda de nasalização = bênça (ão) / sóto (ão) / órfo (ão) / órgo (ão)/ Estêvo(ão)/ Cristóvo(ão)

Quadro 1: Casos de nasalização e desnasalização

$\mathrm{R} / \mathrm{L}$ ficam subtraídos no final = lugá( $\mathrm{r}) / \operatorname{corrê}(\mathrm{r}) /$ alugué(l) / papé(l) / cantá (r) / vê(r)

L trocado por R: armoço/ discurpe/ sordado/ frô/pranta/prano

Supressão $=$ negO $/$ propliedade / supeRtição/ jorná/ só (em vez de jornal e sol)

Assimilação $=\operatorname{tamém}(\mathrm{b}) / \operatorname{correno}(\mathrm{d}) /$ quano $(\mathrm{d})$

$\mathrm{S}$ internamente soa $\mathrm{X}=\mathrm{ceXto} / \mathrm{caXta} / \mathrm{eXtar}$

$\mathrm{B}$ em vez de $\mathrm{V}=$ bassôra / berruga / barrer

$\mathrm{Na}$ língua do povo, todas as palavras terminam em vogal (exceto no plural de determinantes) $=$ os home $/$ duas cadêra $/$ aquelas coisa

Quadro 2: Processos fonológicos consonantais

\section{Ditongo AI torna-se EI = rEIva / REImundo / trEIção}

Supressão de semivogal: caxa/ paxão/ mantêga/ bêjo/ quêjo/ fêjão/lôco/ ôtro/ pôco;

Au e Eu = Ó : Orora / Ómentá (r)/Oropa / Osebo (Eusebio)

$\mathrm{EM}$ no final $=\mathrm{I}$ átono $=$ vágI $/ \operatorname{corágI} / \operatorname{virgI} /$ hômI $/$ ontI

$\mathrm{AM}-3^{\mathrm{a}}$ pes. $\mathrm{Pl}=\mathrm{O}:$ quiser(o) $/$ fizer(o)/ matar(o)

IO / IA átonos, monotongação: cai a semivogal = paciença $/$ negoço $/$ puliça

IO e IA átonos finais palatalizam-se $=$ mobiLHa/ antoNHo/ dimoNHo/ famiLHa.

Dissimilação do LH = mio/ fio/ atrapaiá(r) $/$ teia

Ditongação $-(\mathrm{S})$ ou $(\mathrm{Z})$ finais $=\operatorname{rapa}(\mathrm{I}) \mathrm{z} / \mathrm{pa}(\mathrm{I}) \mathrm{z} /$ está(I)s; (supressão na forma mais popular: rapáI/ máI/ gái - para rapaz/ mas / gás)

E converte-se em I = quI/ dI/ parêdI/ rêdI/ cumpadI/ dI noitI

O reduz-se a $\mathrm{U}$ no final $=$ fechadU $/ \mathrm{riU}(\mathrm{o}) / \mathrm{pombU}$

(E) átono pré-tônico $=(\mathrm{I}): \mathrm{p}(\mathrm{i}) \mathrm{dir} /$ sinhô $/$ tisora 
(E) inicial com S = (i)stação/ (i)spuma/ (i)squadrão

I torna-se Ê: dêreito/ défama/ dêproma/ degladia

Infinitivo com O converte-se em U: cUbrir/ dUrmir / tUssir / IngUlir

O interno = U: dUmingo/ cUmida/ cUrrida/ pUlimento/ lUmbriga/ mUleque / mUinho

Quadro 3: Processos fonológicos vocálicos.

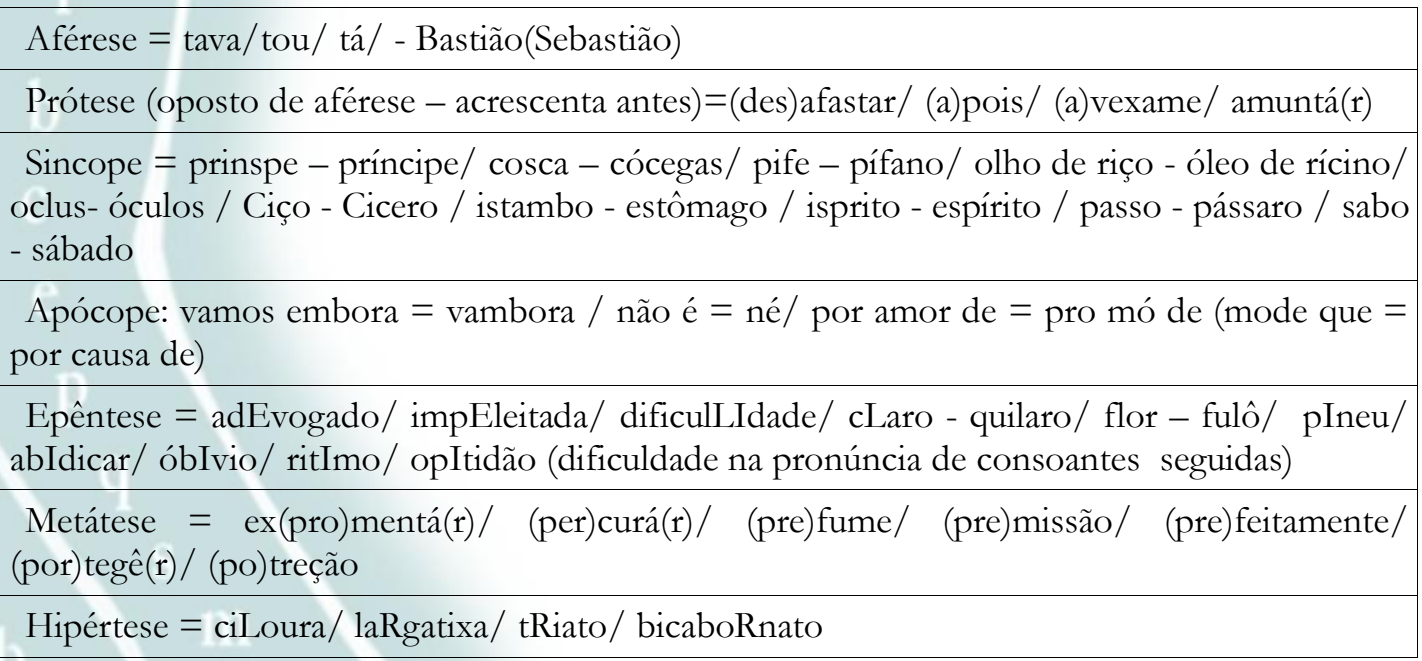

Quadro 4: Figuras de dicção.

\section{MARCAS DA VARIEDADE NORDESTINA EM TEXTOS DE MÚSICA POPULAR BRASILEIRA}

Como se vê em diversos estudos sobre a música popular brasileira, tais quais os de Tinhorão (2013) e Albin (2003), no século XX, essa expressão artística extrapolou a simples função de mero entretenimento e ganhou importância fundamental no plano sociocultural. Justifica-se, assim, a decisão de estudar a expressão da língua nordestina tendo como corpus a música popular. Trata-se, portanto, de reconhecimento do forte papel em nossa sociedade dessa expressão de língua, cultura e arte. Nesse sentido, a canção regional reflete o campo de ações sociais em que se presentificam aspectos dialetológicos fundamentais para entendimento do português brasileiro nordestino. Isso posto, procedemos à análise de três cancões: Asa Branca (Luiz Gonzaga e Humberto Teixeira, 1949), Sussuarana (Heckel Tavares e Luiz Peixoto, 1927), e Assum Preto (Humberto Teixeira / Luiz Gonzaga - 1950). 
Asa Branca (Luiz Gonzaga e Humberto Teixeira -1949)

Quando "oiei" a terra ardendo

Qual fogueira de São João

Eu "preguntei" a Deus do céu, ai,

Por que tamanha judiação

Que braseiro, que "fornaia"

Nem um pé de "prantação"

Por "farta" d'água perdi meu gado

Morreu de sede meu alazão

"Inté" mesmo a asa branca

Bateu asas do sertão

"Entonce" eu disse adeus Rosinha

Guarda contigo meu coração

Hoje longe "muitas légua"

Numa triste solidão

Espero a chuva "caî" de novo

"Pra mim vortá pro" meu sertão

Quando o verde "dos teus oio"

Se "espaiá" na "prantação"

Eu te asseguro não chore não, viu

Que eu "vortarei", viu, Meu coração

Sussuarana (Heckel Tavares e Luiz Peixoto - 1927)

Faiz treis sumana" que na festa de Santana

O Zezé Sussuarana me "chamô pra conversá"

Dessa "bocada nóis saímo" pela "istrada"

Ninguém "num dizia nada, fumo andano divagar"

A noite veio, o caminho "tava em meio"

Eu tive aquele "arreceio" que "arguém" nos pudesse "vê"

Eu quis "dizê", Sussuarana "vamo" embora

"Mais" "Virge" Nossa Senhora, "cadê" boca "pra dizê."

Mais adiante, do mundo já tão distante

"Nóis dois paremo" um instante, "prendemo a suspiração"

"Invregonhado", ele partiu pro meu lado

Ó "Virge" dos "meus pecado", "me dê-me absorvição"

Foi coisa feita, foi "mandinga, foi maleita"

Que nunca mais "endereita", me "botaro", "é capaiz"

Sussuarana, meu coração não me engana

Vai "fazê" "cinco sumana", "tu não vorta" nunca mais. 
Assum Preto (Humberto Teixeira / Luiz Gonzaga - 1950)

Tudo em "vorta" é só beleza

Sol de abril e a mata em "frô"

"Mais" Assum Preto, cego dos "óio"

Num vendo a "luiz", ai, canta de "dô"

"Tarveiz" por "ingnorança"

Ou "mardade" das "pió"

"Furaro os óio" do Assum Preto

Pra ele assim, ai, "cantá mió"

Assum Preto "veve sorto"

"Mais num pode avuá"

"Mil veiz" a sina de uma gaiola

Desde que o céu, ai, pudesse "oiá"

Assum Preto, o meu "cantá"

É tão triste como o teu

Também "robaro" o meu "amô"

Que era a "luiz", ai, "dos óio meu"

Do mesmo modo que procedemos com os fenômenos linguísticos estudados por Mário Marroquim, analisamos os fenômenos que ocorrem nas canções.

\begin{tabular}{|c|c|}
\hline Dados & Análise - destaque \\
\hline $\begin{array}{l}\text { "oiei" "fornaia" "óio" "espaiá" (Asa Branca) } \\
\text { "mió" "óio"- (Assum Preto) }\end{array}$ & 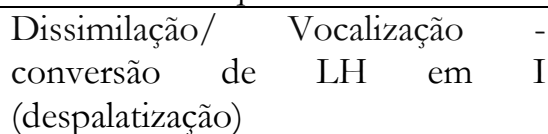 \\
\hline "preguntei" (Asa Branca) "invregonhado" (Sussuarana) & Dissimilação; Metátese \\
\hline $\begin{array}{l}\text { "vortar" "vortarei" "prantação" "farta" (Asa Branca); } \\
\text { "absorvição" "arguém" "vorta" (Sussuarana); "vorta" "frô"” } \\
\text { "mardade" "sorto" tarveiz." (Assum Preto) }\end{array}$ & Conversão de L em R (Rotacismo) \\
\hline $\begin{array}{l}\text { "treis" "Nóis" "capaiz" "mais” (Sussuarana); } \\
\text { "mais "veiz" "tarveiz" "luiz" (Assum Preto) }\end{array}$ & Inserção através de ditongação \\
\hline "arreceio" (Sussuarana); "avuá" (Assum Preto) & Inserção através de prótese \\
\hline "botaro" (Sussuarana); "furaro" "robaro" (Assum Preto) & $\begin{array}{l}\text { Conversão da } 3^{\text {a }} \text { pessoa do plural do } \\
\text { pretérito perfeito AM em O } \\
\text { (desnasalização e monotongação) }\end{array}$ \\
\hline "Virgi" (Sussuarana) & $\begin{array}{l}\text { Desnasalização da postônica, como } \\
\text { ocorre em home e abdome }\end{array}$ \\
\hline "andano" (Sussuarana) & $\begin{array}{l}\text { Assimilação: queda de D, assim } \\
\text { como em correno, pegano etc }\end{array}$ \\
\hline
\end{tabular}




\begin{tabular}{|c|c|}
\hline "saimo" "vamo" "prendemo" (Sussuarana) & $\begin{array}{l}\text { Supressão/apócope de } s \text { de primeira } \\
\text { pessoa do plural }\end{array}$ \\
\hline "tava" (Sussuarana) & Aférese para EStava \\
\hline "divagar" "istrada" (Sussuarana) & Conversão de E em I - assimilação \\
\hline "ingnorança" (Assum Preto) & $\begin{array}{l}\text { Nasalização do I e Monotongação } \\
\text { do IA }\end{array}$ \\
\hline "sumana"'"fumo"paremo"'endereita" (Sussuarana) & Assimilação de vogal \\
\hline "chamô" (Sussuarana) & Monotongação \\
\hline 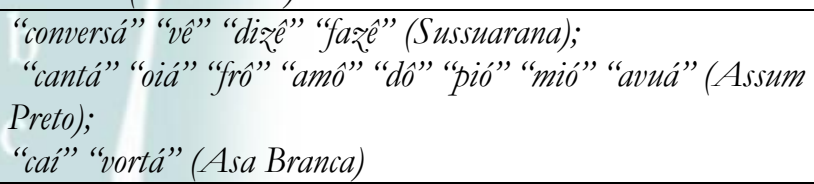 & $\begin{array}{l}\text { Apócope de -r- em infinitivos e em } \\
\text { substantivos }\end{array}$ \\
\hline
\end{tabular}

Quadro 5: Variação fonético-fonológica e figuras de dicção ou metaplasmos

\begin{tabular}{|l|l|}
\hline Dados & Análise - destaque \\
\hline $\begin{array}{l}\text { "muitas légua" "dos teus oio" (Asa Branca); } \\
\begin{array}{c}\text { sumana"(Sussuarana); "mil veiz”(Assum } \\
\text { Preto) }\end{array}\end{array}$ & $\begin{array}{l}\text { Plural sem redundância: a flexão fica no plano do } \\
\text { determinativo (adjuntos) }\end{array}$ \\
\hline “me dê-me" (Sussuarana) & Pleonasmo sintático \\
\hline "num dizra nada" (Sussuarana) & $\begin{array}{l}\text { Negação redundante com pronomes indefinidos } \\
\text { negativos }\end{array}$ \\
\hline "pra mim vortar" (Asa Branca) & $\begin{array}{l}\text { Sintaxe em desacordo com a gramática em } \\
\text { termos de emprego de acusativos ou nominativos } \\
\text { ou dativos }\end{array}$ \\
\hline
\end{tabular}

Quadro 6: Casos morfossintáticos

\begin{tabular}{|l|l|}
\hline Dados & Análise - destaque \\
\hline "Inté" "entonce"(Asa Branca);"suspiração" "bocada” & Arcaísmos regionalistas - conservam \\
"mandinga" "maleita"'"em meio"” "é capaq" (Sussuarana) & formas antigas e marcam o léxico rural \\
\hline
\end{tabular}

Quadro 7: Casos lexicais

Os fenômenos destacados nos quadros 5 a 7 , de nossa autoria, tiveram como escopo a obra de Marroquim aqui referenciada. Entretanto, convém frisar que diversos estudiosos atuais mantêm terminologias e nomenclaturas para tais processos, ao mesmo tempo em que se utilizam de termos criados posteriormente aos estudos classificatórios do autor aqui tomado como base desta pesquisa. Cavaliere (2005), por exemplo, reafirma que processos fonológicos também são denominados de alterações fonéticas ou 
metaplasmos. Tais mecanismos se dão por meio, precipuamente, de adição, supressão, transposição e transformação de fonemas.

Convém, outrossim, frisar que há, nos dias de hoje, um número bem representativo e significativo de pesquisas, trabalhos e publicações acerca dos fenômenos diatópicos/diastráticos e fonético-fonológicos/metaplasmos ora citados e destacados. Quanto ao corpus trabalhado, ressaltamos o fato de que as três canções aqui referidas foram compostas por autores nordestinos, notadamente, Luiz Gonzaga representa o interior de Pernambuco (Exu), assim como Heckel Tavares representa o interior de Alagoas (Satuba), exatamente o foco dos estudos de Mário Marroquim, em A língua do Nordeste: Alagoas e Pernambuco (1934).

Não obstante, essas obras-primas de nosso cancioneiro foram gravadas por uma imensa lista de artistas de diversas regiões do país (e até por artistas do exterior); destaquemos muitos desses artistas: Maria Bethânia, Gal Costa, Fagner, Caetano Veloso, Elis Regina, Tom Zé, Chitãozinho e Xororó, Ney Matogrosso, Badi Assad, Gilberto Gil, Lulu Santos, Hermeto Pascoal, Xangai, Zé Ramalho, Raul Seixas, David Byrne, Dominguinhos, Alcymar Monteiro, Elba Ramalho, Marinês, Maria Eugênia, Inezita Barroso, dentre outros tantos intérpretes. Entretanto, consideramos ser pertinente observar fatos que denunciam profunda incoerência e contradição no registro dessas obras representativas do vernáculo nordestino.

Muitas vezes, por exemplo, os intérpretes dessas canções insistem em não respeitar o emprego da norma não padrão, "corrigindo-a", absurdamente, em prol da norma padrão; Tal fato é facilmente constatado nos registros abundantemente disponibilizados em forma de DVD, programas de televisão, CD, Youtube etc. Mais curioso ainda é perceber que o próprio Luiz Gonzaga nos apresenta gravações de suas canções rigorosamente no dialeto do Nordeste e, em outros momentos, sobretudo em gravações mais recentes, 'corrige' parte das expressões regionais populares que marcam seu cancioneiro, conforme mídias citadas no item anterior; corroborando tais assertivas, podemos comparar diferentes interpretações para Asa Branca, tais como as apresentadas em https://www.kboing.com.br/luiz-gonzaga/asa-branca/; https://www.vagalume.com.br/luiz-gonzaga/asa-branca.html https://www.ouvirmusica.com.br/luiz-gonzaga/47081/.

Outro aspecto que nos causou estranheza durante a pesquisa foi o fato de a maioria das fontes que transcrevem as letras das músicas, sobretudo em encartes de discos, na internet, como se vê acima, e nos subtítulos de DVD, achar adequado, necessário e conveniente pôr entre aspas ou itálico as expressões consideradas erradas, desvios de norma padrão. Se isso já seria, a nosso ver, uma incoerência e uma confirmação de juízo de valor, o que dizer, então, do fato de tais destaques surgirem em certas expressões regionais e não aparecerem em outras do mesmo texto na mesma fonte? Ou, mais grave ainda, as mesmas expressões ora são 'corrigidas' ora não. 
Nessa mesma direção, encontramos a canção Assum Preto em diferentes mídias, como as listadas a seguir: https://www.letras.mus.br/luiz-gonzaga/47082/; https://www.youtube.com/watch?v $=z$ U9SqFDSdj4 https://www.youtube.com/watch?v=1J2vbp4Flpc.

O mesmo pode ser observado em Sussuarana: https://www.letras.mus.br/mariabethania/1021255/; https://www.letras.com.br/hekel-tavares/sucuarana ehttp://tvcultura.com.br/videos/44572 sussuarana-por-inezita-barroso.html

A valorização e o respeito a esse registro linguístico presente na música popular 'de raiz' precisam ser evidenciados e trabalhados inclusive em sala de aula, conforme sugerem Coan e Freitag (2010), evitando-se reforçar a ideia de um português certo e hegemônico em contraposição a um português 'errado' e de menor (ou sem) valor que, portanto, carece de 'correção'. 'Passar para outra norma, por exemplo, a letra das canções de Luiz Gonzaga ou os poemas de Patativa do Assaré é apagar desses textos a marca de seu enraizamento cultural. É tirar-lhes seu sabor, seu gosto de terra; sua graça. É desfazê-los, afinal" (ANTUNES, 2007, p. 108).

Isso posto, consideramos equívoco e desrespeito contumaz e deliberado numa perspectiva sociolinguística o que fora detectado e apresentado por meio da abordagem e análise com acuidade ante nossa amostragem. Convém reiterar que fizemos aqui uma abordagem metodológica qualitativa, limitada a um recorte acerca das marcas caracterizadoras do vernáculo nordestino, sobretudo, seus aspectos fonético-fonológicos presentes na canção popular, elemento dos mais representativos da cultura, arte e identidade brasileiras. Por isso, por conseguinte, destacamos apenas os fenômenos dialetais mais evidentes e corriqueiros da língua até hoje em uso abundante por parte dos nordestinos.

Cabe, ainda, ressaltar que, com a mesma riqueza de ocorrências dos fenômenos sociolinguísticos aqui demonstrados através das três canções de nosso corpus, podemos citar outras obras também clássicas, dentre tantas outras, de nosso cancioneiro, tais quais:

1. Cuitelinho - composição do folclore do Brasil Central recolhida e musicada por Paulo Vanzolini e Antônio Xandó;

2. Acauã, além de tantas outras obras de Luiz Gonzaga;

3. Saudosa Maloca e Samba do Arnesto - Adoniiran Barbosa - variedade caipira de São Paulo;

4. A Marvada Pinga - Ochelsis Laurean - sucesso maior de Inezita Barroso (marcas múltiplas de variação diatópica e diastrática).

\section{CONSIDERAÇÕES FINAIS}

À guisa de conclusões, ressaltamos que destacamos na primeira parte deste texto as contribuições mais relevantes de cada período dos estudos dialetológicos brasileiros: na 
primeira fase, o maior relevo se encontra no registro de realidades lexicais, glossários regionais, por exemplo; já a segunda fase traz como grande marca a ampliação dos estudos da primeira, por meio de uma produção mais vasta que a do período anterior. Em se tratando de momentos da cronologia de estudos dialetais no Brasil, não se pode negar o rico contributo de Suzana Cardoso e Carlota Ferreira pela proposição de estabelecer a terceira fase, dimensionada pelo desenvolvimento da geolinguística no pais, credibilizada pelo próprio governo no incentivo a que se criasse o Atlas Linguístico Brasileiro; por fim, Jacira Mota e Suzana Cardoso demarcam 1996 como marco de advento da quarta e atual fase.

Isso se deu pela constatação de necessidade de retomada do projeto de publicação do Atlas Linguístico Brasileiro, incorporando a grande contribuição trazida pela produção de atlas de segunda e terceira gerações. Em seguida, vimos que na obra $A$ língua do nordeste, nos anos de 1930, o autor já traz aspectos bem modernos, a ponto de considerar "Gramática como instrumento de tortura: regras artificiais de uma língua sem força de expressão".

Nesse sentido, destaca "profunda riqueza do vocabulário nordestino", fazendo uma crítica ao fato de a escola insistir em ensinar a língua de Portugal aos brasileiros. Em contrapartida, o mesmo Mário Marroquim usa termos como: - Solecismos vulgares do povo iletrado/ - O povo tem limitações, poucos elementos, vocabulário reduzido, horizonte limitadíssimo, ou seja, em sentenças do tipo: "Os menino tava tudo queto", considera o autor que há séculos de isolamento, abandono e ignorância.

Lamentavelmente, visões tão controvertidas daquela época reverberam ainda em nossos dias. Em suma, se hoje, por um lado, não há dúvidas sobre o valor artístico-cultural da obra de autênticos poetas como Luiz Gonzaga, Humberto Teixeira, Heckel Tavares, Luiz Peixoto, Patativa do Assaré, Adoniran Barbosa, dentre tantos outros que legitimam o português da realidade diatópica e diastrática do Brasil por meio da canção popular, não se deve deixar de repudiar uma visão discriminadora que, por outro lado, ainda encontra eco nos meios urbanos e elitizados, mesmo após quase cem anos de Modernismo e da obra de Oswald de Andrade, Mário de Andrade, Manuel Bandeira etc., que já traziam discussões metalinguísticas como essas.

Isso se não mencionássemos a importância vital das obras produzidas desde a primeira fase dos estudos dialetológicos no Brasil e as contribuições vultosas de trabalhos como os de Amadeu Amaral, Antenor Nascentes e, especificamente, em nossa pesquisa, Mário Marroquim.

\section{REFERÊNCIAS}

ALBIN, Ricardo Cravo. O livro de ouro da MPB. Rio de Janeiro: Ediouro, 2003. 
AGUILERA, Vanderci de Andrade (Org.). A Geolingü̈́stica no Brasil. Trilhas seguidas, caminhos a percorrer. Londrina: Eduel, 2005.

ANTUNES, Irandé. Muito além da gramática: por um ensino de línguas sem pedras no caminho. 3. ed. São Paulo: Parábola Editorial, 2007.

BAGNO, Marcos. Preconceito linguístico: o que é, como se faz. 51. ed. São Paulo: Loyola, 2009.

CARDOSO, Suzana. Geolinguística: tradição e modernidade. São Paulo: Parábola, 2010.

CAVALIERE, Ricardo. Pontos essenciais em fonética e fonologia. Rio de Janeiro: Lucerna, 2005.

COAN, M.; FREITAG, R. M. K. Sociolinguística variacionista: pressupostos teóricometodológicos e propostas de ensino. Domínios de Lingu@gem, v. 4, n. 2, p. 173-194, 2010.

FERREIRA, Carlota e CARDOSO, Suzana. A dialetologia no Brasil. São Paulo: Contexto, 1994.

FREITAG, Raquel Meister Ko. Sociolinguística no/do Brasil. Cadernos de Estudos Linguísticos, v. 58, n. 3, p. 445-460, 2016.

LEITE, Marli Quadros. Preconceito e intolerância na linguagem. 2. ed. São Paulo: Contexto, 2012.

MARROQUIM, Mário. A língua do Nordeste: Alagoas e Pernambuco. São Paulo: Nacional, 1934.

MATTOS E SILVA, Rosa Virgínia. O português são dois... novas fronteiras, velhos problemas. 2. ed. São Paulo: Parábola Editorial, 2006.

TINHORÃO, J. R. História social da música popular brasileira. 2. ed. São Paulo: 34, 2013.

Recebido em: $12 / 12 / 2017$

Aprovado em: 26/01/2018

Publicado em: 01/03/2018 